\title{
How the Structure of the Sweat Glands of Camel Symphonizes their Reliable Function
}

\author{
Mohammad Rashad Fath El-bab ${ }^{1}$, Alaa Sayed Abou-Elhamd ${ }^{1,2}$, Mahmoud Abd-Elkareem $^{1}$
}

\begin{abstract}
${ }^{1}$ Department of Anatomy, Histology and Embryology, Faculty of Veterinary Medicine, Assiut University, Assiut, Egypt; ${ }^{2}$ Department of Biology, Faculty of Medicine, Jazan University, Jazan, Saudi Arabia.
\end{abstract}

\begin{abstract}
It is well known that camels can live in severe environmental conditions and have ability to regulate its body temperature in such conditions. Previous studies indicated that skin is playing a pivotal role in thermoregulation and adaptation of the body to the surrounding environment. The aim of the current study is to investigate the role of the sweat glands of camel in their adaptation to the surrounding environment. The microstructure of the sweat glands in nine body regions of 10 camels has been studied. The sweat glands were found to be distributed in association with each primary hair follicle. Their ducts open into the upper portion of the hair follicle at a peculiar destination device. The correlated reliable function was discussed.
\end{abstract}

Keywords | Camel, Body temperature, Sweat glands

Editor $\mid$ Asghar Ali Kamboh, Sindh Agriculture University, Tandojam, Pakistan.

Received | December 16, 2016; Accepted | January 17, 2017; Published | January 30, 2017

*Correspondence | Alaa Sayed Abou-Elhamd, Department of Anatomy, Histology and Embryology, Faculty of Veterinary Medicine, Assiut University, Assiut City, 71526 Egypt; Email: alaa88@yahoo.com.

Citation | Fath El-Bab MR, Abou-Elhamd AS, Abd-Elkareem M (2017). How the structure of the sweat glands of camel symphonizes their reliable function. J. Anim. Health Prod. 5(1): 19-23.

DOI | http://dx.doi.org/10.14737/journal.jahp/2017/5.1.19.23

ISSN (Online) | 2307-8316; ISSN (Print) | 2309-3331

Copyright (C) 2017 El-bab et al. This is an open access article distributed under the Creative Commons Attribution License, which permits unrestricted use, distribution, and reproduction in any medium, provided the original work is properly cited.

\section{INTRODUCTION}

$\mathrm{D}$ romedaries are among the large mammalian species. They are found mostly in semi-arid and arid areas with long dry seasons. As well as they are significantly adapted for coping with water deprivation (Köhler-Rollefson, 1991; Kewan, 2003; Hekal, 2014). Skin is a complex architectural blend of tissue and it is not only the largest organ covering the body surface but also it plays an important role in the adaptation of the animal to desert life and aiding in thermoregulation and water balance (Pfeiffer et al., 2006; Wilke et al., 2007; Gbolagunte, 2016).

Although the histomorphological features of the sweat glands have been investigated in various animal species; Horses (Obayes, 2016), dogs (Ogunkoya, et al., 2007; Aughey and Frye, 2011; Bacha and Bacha, 2012), cattle (Jenkinson and Nay, 1975; Nascimento et al., 2015), water buffaloes (Jenkinson and Nay, 1975; Abdul-Raheem et al., 2009), goats and sheep (Jenkinson and Nay, 1975), camels (Lee and Schmidt-Nielsen, 1962; Kamel et al., 1986; Alkafafy et al., 2011, Wiam et al., 2013; Gbolagunte, 2016) and llama (Atlee, et al., 1997), yet the histological structure of the sweat glands in camels was scarcely traced in the available literature.

The present investigation aims to study the micromorphological peculiarities of the sweat glands in correlation to its reliable function in camels.

\section{MATERIALS AND METHODS}

The skin samples used in this study were obtained from 10 camels, of both sexes, ranging between 2 months and 7 years old. The samples were collected from Beni-Adi slaughter house, Assiut province, Egypt. The samples were 
taken from the front, neck, shoulder, back, belly, chest, thigh, flank and tail regions of the body.

The collected materials were fixed in $10 \%$ neutral buffered formalin and Bouin's solution. The samples were then processed for embedding in paraplast blocks. Sections were cut $(5 \mu \mathrm{m})$ serially. The paraffin sections were stained by Harris's Haematoxylin and eosin (Harris, 1900) and Crossmon's trichrome stains (Crossmon, 1937).

Small samples of the skin $(1-2 \mathrm{~mm})$ were fixed by using paraformaldehyde- glutraldehyde fixative (Karnovsky, 1965). After fixation, the samples were washed in 0.1M phosphate buffer and osmicated in 1\% Osmium tetroxide in $0.1 \mathrm{M} \mathrm{Na}$-cacodylate buffer at $\mathrm{pH}$ 7.3. After that, the samples were dehydrated in a graded series of ethanol followed by propylene oxide, and embedded in Araldite. Semithin sections $(1 \mu \mathrm{m})$, were cut and stained with toluidine blue.

All presented micrographs are labelled as the magnification with microscope before photographic enlarging.

\section{RESULTS}

The sweat glands in camels are of the simple tubular exocrine variety. They are large glands which always secrete into an adjacent primary hair follicle; epitrichial sweat glands (Figure 1).

The glands are composed of two portions; namely, the secretory portion and the excretory duct.

The secretory portion (adenomeres) of the gland, being of the coiled, tubular type with a widely dilated lumen, is located in the dermis at a level one fold deeper than that of the hair papillae (Figure 1). The secretory portion is lined by high cuboidal or columnar cells. The apical portion of some cells bears a budding appearance (cytoplasmic blebbing). The cytoplasm presents numerous basophilic granules at the apical portion of the cells (Figure 2). The nucleus is rounded or oval and centrally located. The glands have a discontinuous layer of myoepithelial cells between the secretory cells and the basement membrane (Figure 2).

The secretory end-piece leads suddenly to a distinctively narrow excretory duct reaching 1:4 the diameter of that of the secretory portion (Figure 1 and $3 \mathrm{~A}-\mathrm{B}$ ). The ducts, pursuing a slightly wavy pattern run parallel to the neighbouring hair follicle in their way to open into the bottom of a peculiar destination device. The latter device is found at the outer most portion of the accompanying primary hair follicle in the vicinity of the epidermis. The ducts may open onto the surface of the skin in an interfollicular location (atrichial sweat gland) by a similar pattern. The excre-

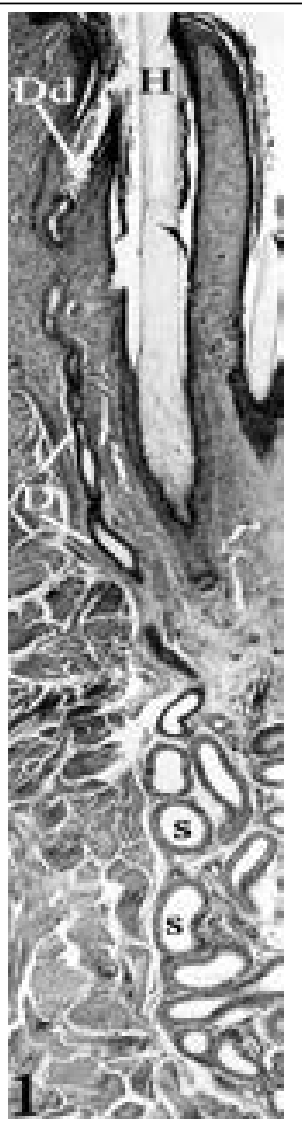

Figure 1: An epitrichial sweat gland at the thigh region of seven years-old camel, consisting of two portions: the secretory portion (S) and the excretory duct (D) opening into the primary hair follicle in the nearby of the epidermis. Dilated destination device (Dd), primary hair $(\mathrm{H}) . \mathrm{H} \& \mathrm{E}$, X100.

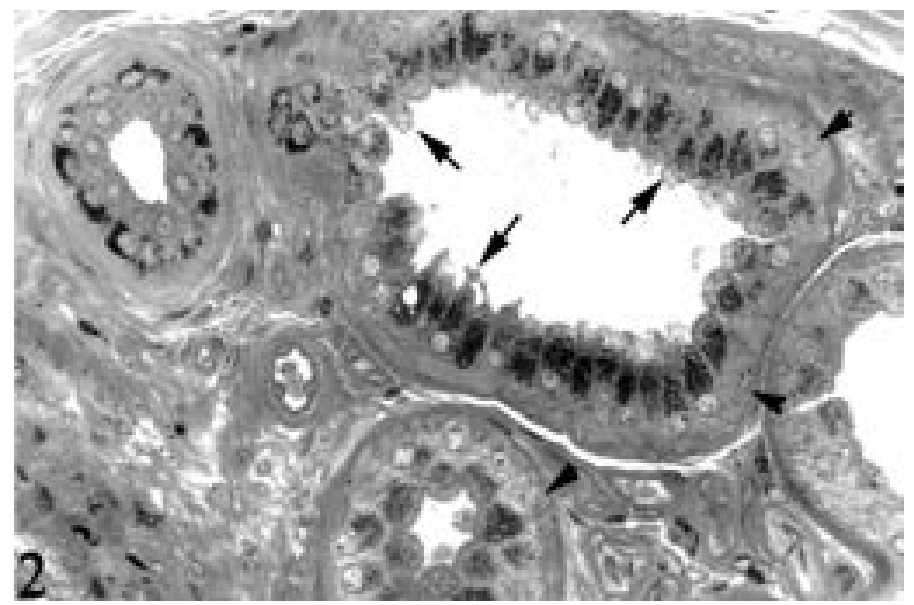

Figure 2: The secretory end-pieces of the epitrichial sweat glands at the thigh region of 6 years-old camel, showing numerous basophilic granules at the apical portion of the cells. Some cells bear a budding appearance (Cytoplasmic blebbing, arrows) apically. Myoepithelial cells (Arrowheads). Toluidine blue, X400.

tory duct being lined by two layers of cuboidal epithelium, receives a conical jacket of stratified epithelium towards its way to open into the neighbouring primary hair follicle (Figure 3C-D). The terminal portion of the duct, reach- 
ing the apex of the destination device, runs further inwards forming nozzle-shaped extension which projects into the bottom of the destination device (Figure 4, 5 and 6A-B). The tubular terminal portion of the duct is composed of 3-6 flattened or cuboidal cells-long pipe (Figure 6A-B).

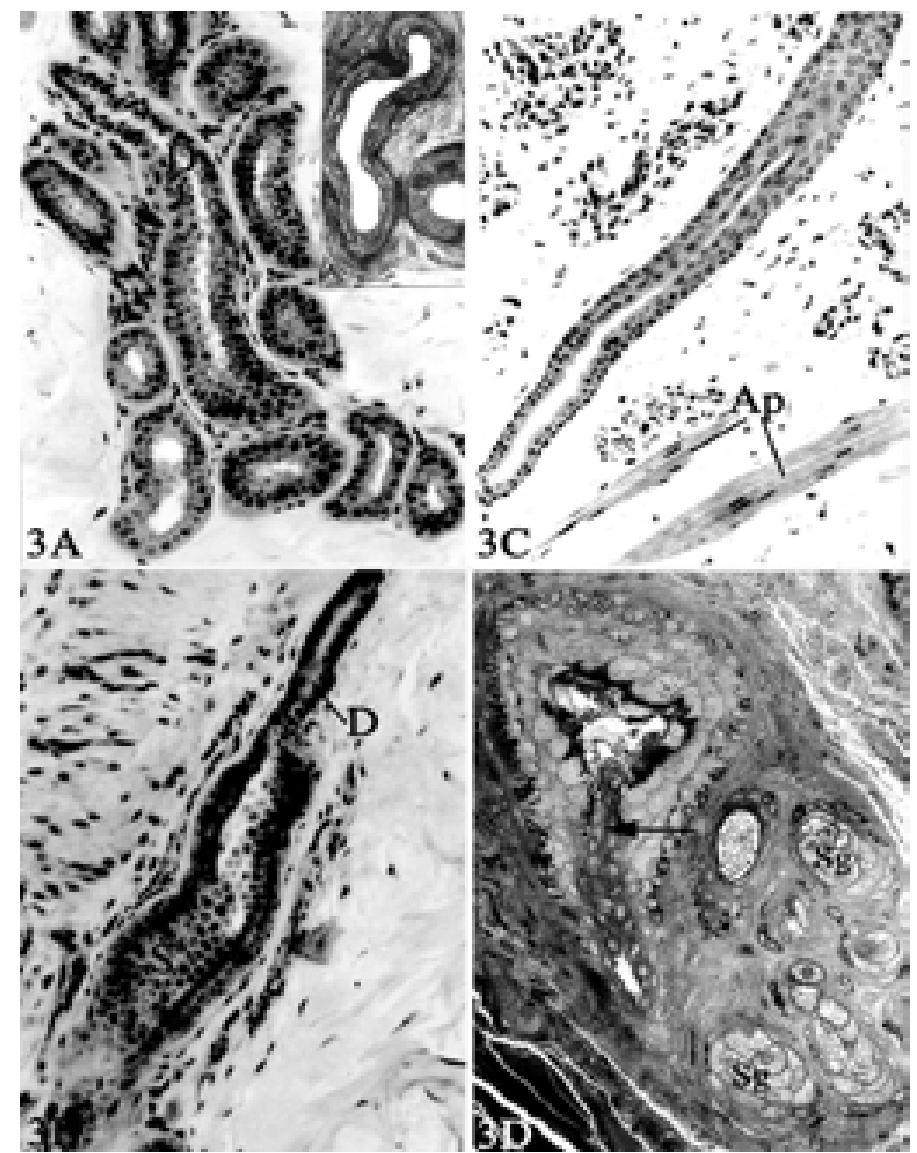

Figure 3(A-D): 3A, The secretory portion of the epitrichial sweat gland at the belly region of 6 months-old camel, showing the commencement of the excretory duct (D), secretory portion (S). Toluidine blue, X160. Inset: The excretory duct at the thigh region of 6 years-old camel, showing a wavy pattern in their way to open into a primary hair follicle. Toluidine blue, X250. 3B, The transition between the secretory portion $(\mathrm{S})$ and the excretory duct (D) at the neck region, of 3 years-old camel. Toluidine blue X160.3C, The excretory duct of the epitrichial sweat gland at the shoulder region, towards its opening into the primary hair follicle (upwards), Ap= Arrector pili muscle. Toluidine blue, X160. 3D, The excretory duct (arrow), receiving a conical jacket of stratified epithelium, in its way to open into the apex of the destination device, sebaceous gland (Sg). Toluidine blue, X 250.

The destination device is represented by a dilatation of various shapes. It may be oval-, flask-, triangular- or rounded-shaped (Figure 6A-B). It joins the hair follicle by its base "mouth" at a level higher than that of the sebaceous gland. It receives the terminal portion of the excretory duct at its apex. The destination device is lined by cornified stratified epithelium, consisting of 5-7 layers in thickness
(Figure 4 and 6A-B). The basal layer is composed of one row of cuboidal cells showing numerous melanin pigments within their cytoplasm. The middle layer is composed of about 5 rows of large polyhedral cells which increase in size towards the surface where the largest cells are demonstrated. The cytoplasm is peculiarly pale harbouring large, rounded, central, vesicular nucleus. The cells of the middle layer present fewer amount of intracytoplasmic melanin.

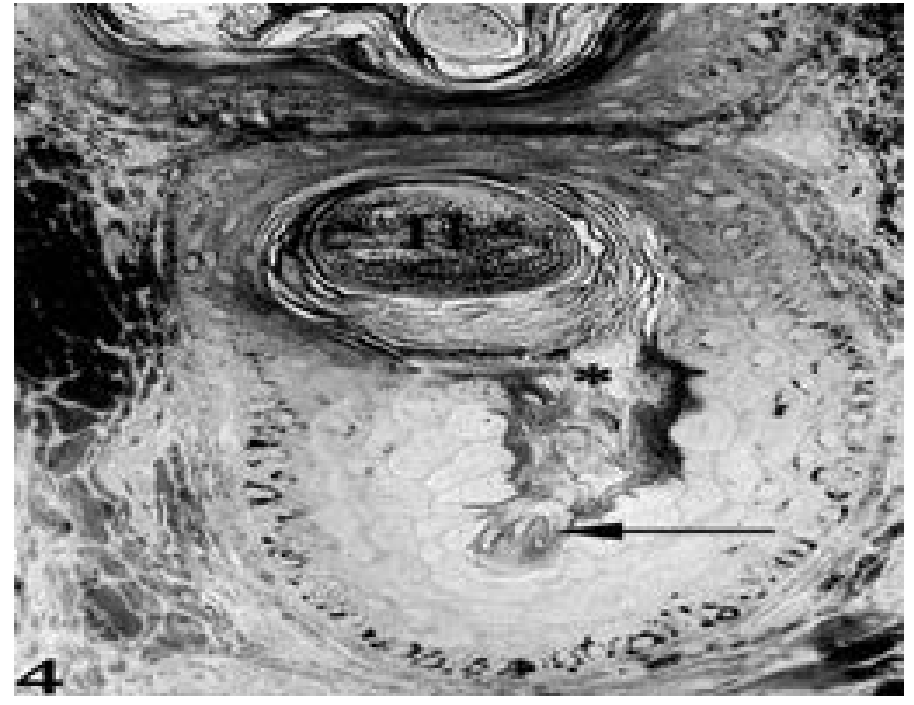

Figure 4: Cross section of the hair follicle at the level of the dilated destination device, at the thigh region, of six years-old camel, showing the nozzle-shaped terminal portion of the excretory duct (arrow) and the opening of this device into a neighbouring hair follicle $\left(^{*}\right)$. Notice the histomorphological differences between the epithelial lining of the hair follicle and that of the dilated device. Primary hair (H), Toluidine blue, X250.

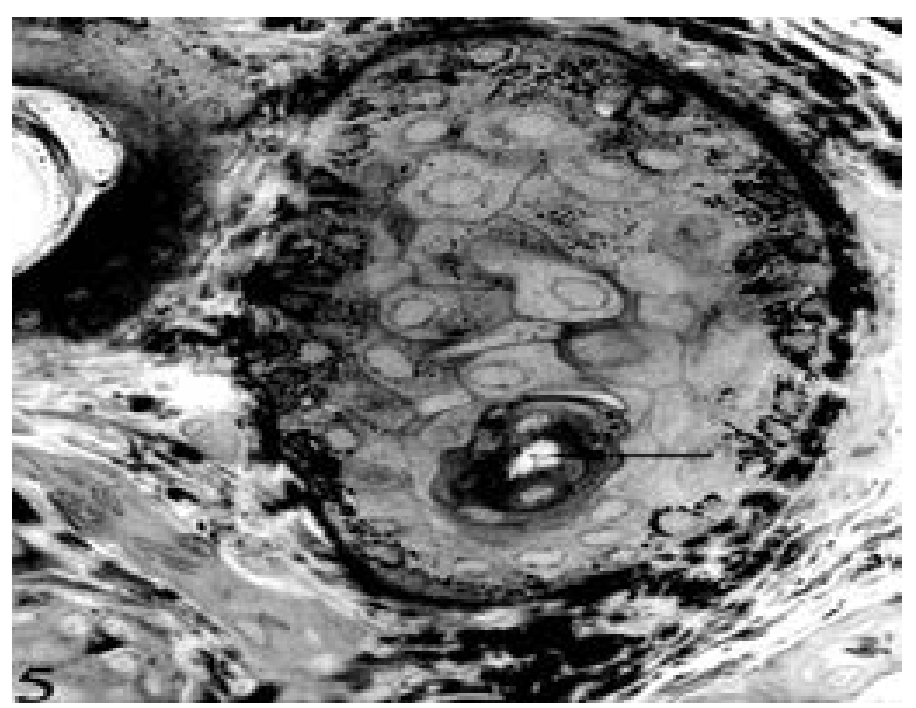

Figure 5: Tangential section of the destination dilated device, showing the peculiar cellular elements of the lining epithelium, at the thigh region of six years-old camel. Excretory duct (arrow), Toluidine blue, X250.

The superficial layer is formed of several layers of keratiniz- 

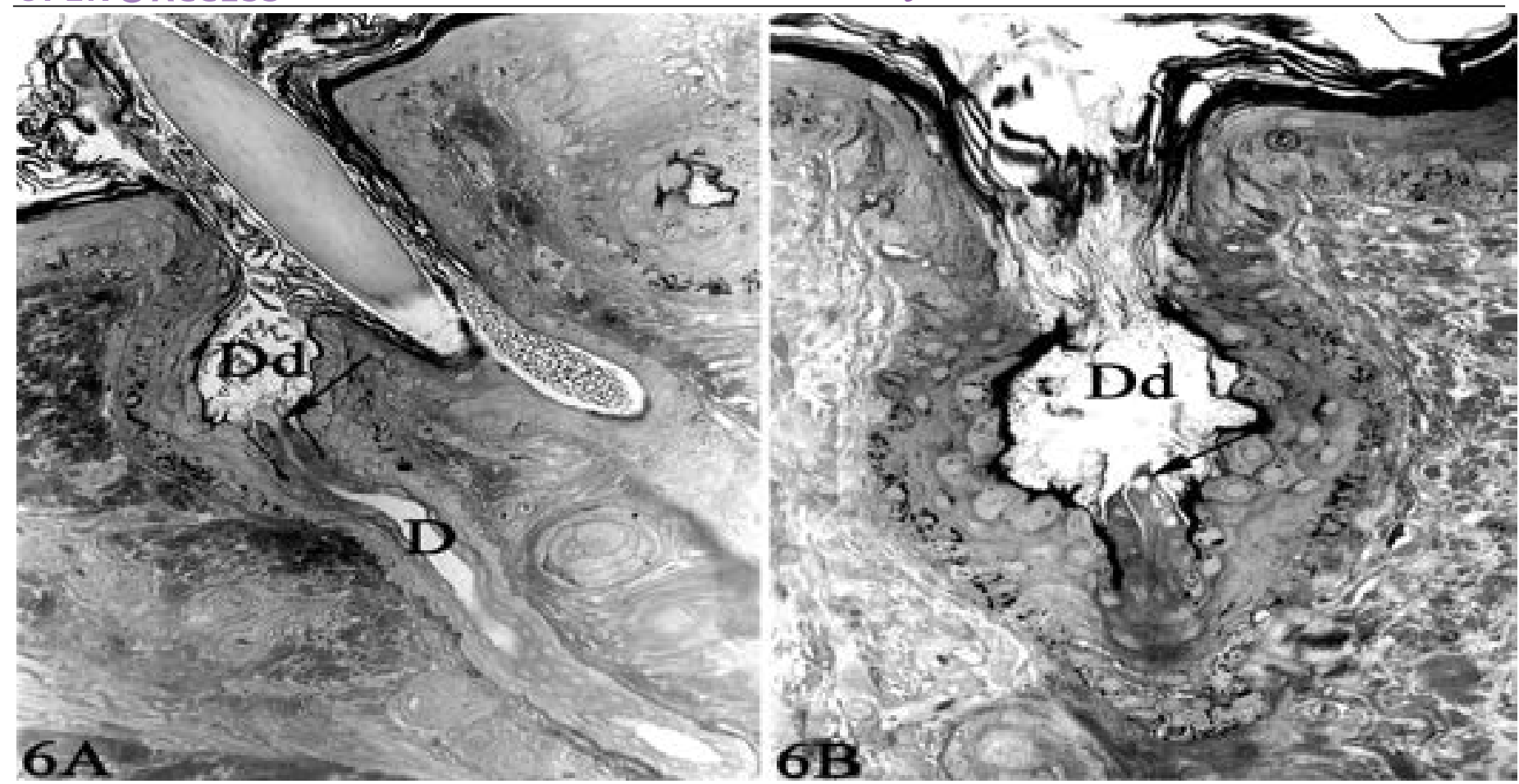

Figure 6 (A \& B): The terminal portion of the excretory duct (D) opening into an oval or rounded-shaped dilated destination device (Dd) at the outer most portion of a primary hair follicle (epitrichial sweat gland "A") or emptying on to the skin surface in an interfollicular location (atrichial sweat gland "B"). Notice the terminal portion of excretory duct (arrow) projecting into the lumen of the dilated destination device. Toluidine blue, X250.

ed material which fills the lumen and condenses at the aperture of the device into the primary hair follicle and or the surface of the skin. The flask-shaped dilatations are surrounded with a highly vascular connective tissue.

\section{DISCUSSION}

Although the structure of the sweat glands in one-humped camels resemble coarsely that of other animal species, yet they are uniquely characterized by special features which fit the organ to correlated functions required to adapt the arid climatic conditions, where the camel lives and raises.

The presence of the sweat glands into the deeper layers of the dermis of the camel in addition to the coiled nature of its secretory end-pieces indicates a pattern which reflects the role of these glands in regulation of body temperature. Sweating increases heat loss. Vaporization of water on the skin and mucous membranes of the mouth and respiratory passages is considered as a major process for transferring heat from the body. Vaporization of $1 \mathrm{~g}$ of water removes about $0.6 \mathrm{Kcal}$ of heat. When sweat secretion is increased, the degree to which the sweat vaporises depends upon the humidity of the environment (Ganong, 1983). The latter author added that the body heat lost by vaporization of sweat reaches a percentage of $27 \%$ at $21^{\circ} \mathrm{C}$. Burr (Burr, 1993) reported that sweat evaporation depends upon the difference between the vapor pressure of sweat on the skin and that of water in the air adjacent to the skin.
Based on scientific mechanical hypothesis, the terminal portions of the excretory ducts are structurally oriented in such a way as to impart the architectural characteristics which serve to retain a more or less definite quantity of secretory fluid within the dilated destination devices. The temperature of this retained quantity of secretion is controlled by blood circulating within the plentiful blood vascular elements surrounding the before-mentioned dilatations.

In addition, the retained secretory fluid into the dilatation devices supported by the several layer of keratinized material, which fills the lumen and condenses at the aperture of the device, provided a humid medium which acts to influence further flow of secretion from the secretory end-pieces. A phenomenon which is substantially supported the obviously narrow lumen of the excretory duct. The unique structure of the stratum corneum of the skin contributes to its function as a barrier to water loss and external harsh environment (Marino, 2006).

Moreover, the architectural structure of the terminal portion of the excretory duct and its mode of connection to the bottom of the destination device may service as a mode of valve system. A matter which is achieved by exerting pressure on the "nozzle" portion of the excretory duct by the collected secretory fluid, leading to its closure, presenting a mode of control on the flow of the secretory fluid. 


\section{1- 170 .}

- Harris HF (1900). On the rapid conversion of haematoxylin into haematin in staining reactions. J. Appl. Microsc. Lab. methods, 3: 777. Cited by Bancroft JD and Steven A (1996).

The structural orientation of the terminal portion of the excretory duct of the sweat glands of camels play an important role in acclimatization of camels to harsh environmental condition by retaining more or less definite quantity of secretory fluid within the dilated destination devices.

\section{ACKNOWLEDGMENTS}

We would like to thank the technician in the department of anatomy and histology, faculty of veterinary medicine, Assiut University for their help during sampling and processing.

\section{CONFLICT OF INTEREST}

The authors declare that they have no competing interests

\section{AUTHORS CONTRIBUTION}

All authors contribute in collection and processing of samples. Image was taken by Fath-Elbab and Abd-Elkareem. Labeling of Figures was performed by Abou-Elhamd. Writing of the manuscript was performed by Fath-Elbab and Abou-Elhamd

\section{REFERENCES}

-Abdul-Raheem MH, Ahmed NS, Al-Haaik AG (2009). Histological and topographical study of the skin of native buffalo. Iraqi J. Vet. Sci. 23(2).

-Alkafafy M, Rashed R, Emara S, Nada M, Helal A (2011). Histological and immunohistochemical studies on the epididymal duct in the dromedary camel (Camelus dromedarius). Anat. Cell Biol. 44(4):284-294. https://doi. org/10.5115/acb.2011.44.4.284

-Atlee BA,Stannard AA, Fowler ME,Willemse T,Ihrke PJ, Olivry $\mathrm{T}$ (1997). The histology of normal llama skin. Vet. Dermatol. 8: 165-176. https://doi.org/10.1046/j.1365-3164.1997.d0113.x

-Aughey E, Frye FL (2011). Comparative Veterinary Histology with Clinical Correlates: CRC Press.

-Bacha WJ, Bacha LM (2012). Color Atlas of Veterinary Histology, 3 edn: Wiley.

- Burr RE (1993). Medical aspects of cold weather operations: A handbook for medical officers: US Army Research Institute of Environmental Medicine Natick, Massachusetts.

- Crossmon G (1937). A modification of Mallory's connective tissue stain with discussion of the principle involved. Anat. Rec., 69: 33-38. Cited by Bock, P. (1989) in Romies Mikroscopishe Technik. 17 Aufl. Ubran and Schwarzenberg. Munchen. Wiein- Baltimore.

- Ganong WF (1983). Review of medical physiology, 11 edn. Los Altos California: Lange medical publication.

- Gbolagunte GD (2016). Reclassification of the sweat glands of the one-humped camel (Camelus dromedarius) as apoeccrine based on mode of secretion and extrusion. 4(5):
- Hekal SA (2014). Histological Study of the Skin and Leather Characteristics in Two Types of Arabian Camels (Camelus dromedarius). J. Am. Sci. 10(9).

-Jenkinson DM, Nay T (1975). The sweat glands and hair follicles of different species of bovidae. Aust. J. Biol. Sci. 28(1): 55-68.

- Kamel G, Schwarz R, Ali AMA (1986). Studies on the hair follicles and apocrine tubular glands in the skin of the onehumped camel. Assiut. Vet. Med. J. 17(34): 55-65.

-Karnovsky MJ (1965). A formaldehyde-glutraldehyde fixative of high osmolarity for use in electron microscopy. J. Cell Biol. 27:137A.

-Kewan KZE (2003). Studies on camel nutrition. Faculty of Agriculture. PhD.

-Köhler-Rollefson (1991). Camelus dromedarius. Mamm. Species. 375: 1- 8 .

- Lee DG, Schmidt-Nielsen K (1962). The skin, sweat glands and hair follicles of the camel (camelus dromedarius). Anat. Rec. 143(1):71-77. https://doi.org/10.1002/ar.1091430107

- Marino C. Skin physiology, irritants, dry skin and moisturizers. In. Washington: Washington State Department of Labor and Industries; 2006: 1-13.

- Nascimento MRBdM, Dias EA, Santos TRd, Ayres GF, Nascimento CCN, Beletti ME (2015). Effects of age on histological parameters of the sweat glands of Nellore cattle. Rev. Ceres. 62(2).

- Obayes AK (2016). Histological study for skin of horse. Tikrit J. Pure Sci. 21(1). Histology of the exocrine glands of The canine perianal Skin. Nig. Vet. J. 28(2): 33- 38.

- Pfeiffer CJ, A.H.K.Osman, Pfeiffer DC (2006). Ultrastructural analysis of the integument of a desert-adapted mammal, the one-humped camel (Camelus dromedarius). Anat. Histol. Embryol. 35:97- 103. https://doi.org/10.1111/j.14390264.2005.00644.x

-Wiam IM, Sonfada ML, Yahaya A, Umar AA. Morphometric study of the skin in different anatomical regions of the camel (Camelus dromedarius). In: Proceedings of the International Camel Conference, Al-Hasa, Saudi Arabia. Camel Publishing House 2013: 17-21.

-Wilke K, Martin A, Terstegen L, Biel SS (2007). A short history of sweat gland biology. Int. J. Cosmet. Sci. 29(3):169-179. https://doi.org/10.1111/j.1467-2494.2007.00387.x
- Ogunkoya YO, Ema AN, Ghaji A, Adogwa AO (2007). 